\title{
VALIDATION OF THE LEARNING TRANSFER SYSTEM INVENTORY IN THE SOUTH AFRICAN CONTEXT (PART 1)
}

\author{
W J COETSEE \\ jc@rau.ac.za \\ Department of Human Resource Management \\ University of Johannesburg \\ R EISELEN \\ Statistical Consultation Service \\ University of Johannesburg \\ J. BASSON \\ Department of Human Resource Management \\ University of Pretoria
}

\begin{abstract}
The purpose of this study was to validate the Learning Transfer System Inventory (LTSI) in the South African context. The sample used in this study was a convenience sample of 240 employees working for a Banking group. Exploratory factor analysis of the LTSI was used to determine if an interpretable factor structure of latent transfer system constructs when applied in the South African context could be identified. From the results it appears that the factor structure of the LTSI, as revealed by means of the exploratory approach, appears differently in the South African context.
\end{abstract}

Key words

Validate, Learning Transfer System Inventory

\begin{abstract}
The new business paradigm, which manifests in aspects such as new forms of business structures and management practices, requires organisations to exploit intellectual assets, which in turn necessitates a renewed focus on the development of human resources. Development interventions require a substantial allocation of financial, human and time resources, but there is little evidence in research that the skills, knowledge and behaviour learnt in training programmes are transferred to the job or result in changed behaviour in the workplace (Baldwin \& Ford, 1988; Ford \& Weissbein, 1997; Gist, Bavetta \& Stevens, 1990). This implies that learned behaviour is not generalised to the job context and maintained over a period of time in the job. The most commonly cited estimate in the literature is that only $10 \%$ of learning is transferred to improved job performance (Holton \& Baldwin, 2000).
\end{abstract}

Organisations tend to either avoid evaluating Human Resource Development interventions, or alternatively, evaluate only a few facets of an intervention. This could be ascribed, in part, to the complex nature of evaluations. When evaluation is indeed done by organisations, evaluation taxonomies often serve as the only evaluation methods. Because of the inherent nature of taxonomies (namely to categorise), the results gained offer very little towards illustrating the contribution of an intervention towards improved organisational effectiveness. Furthermore, important variables existing on individual, group and organisational level that could influence the effectiveness of the training intervention effectiveness of learning transfer, have been excluded from various evaluation approaches. This includes, for example, the learning readiness of the individual (Knowles 1984), an aspect that is related to both group functioning (Watkins \& Marsick 1993) and organisational aspects (Tracy, Tannenbaum \& Kavanagh 1995).

Learning transfer can be considered one of the fundamental cornerstones in the establishment of a learning organisation (Senge, 1990); to enable an organisation to utilize learned knowledge, skills and behaviour acquired during a learning event, learning transfer must take place between the classroom and the workplace. Baldwin and Ford (1988) as well as Ford and
Weissbein (1997) define transfer as “... generalisation of the skills acquired during a learning event to the work environment and the maintenance of the acquired skills over time". Further to the preceding statement Broad and Newstrom (1992) state that transfer of training can be defined as "the effective and continuing application, by trainees to their jobs, of the knowledge and skills gained in training - both on and off the job". From the definitions, one can concur that there is consensus that the transfer of learning involves the application, generalisability and maintenance of newly-learned knowledge and skills. There is, however, no concensus regarding which factors influence learning transfer. Table 1 gives a concise layout of the most important components and variables cited in literature that could influence the effectiveness of learning transfer.

From Table 1 it can be seen that there are numerous factors that could influence the effectiveness of an intervention. It is almost impossible to make an informed decision regarding the effectiveness of an HRD intervention if the stated variables are not taken into consideration. Furthermore, various reasons are cited why learning transfer occurs on a limited basis and Ford and Weissbein (1997) state in this regard that:

- There is a lack of conceptual models driving the choice of variables which should be examined for their impact on transfer;

- Variables that may impact on transfer are poorly conceptualised and operationalised;

- Practitioners do not have a thorough understanding of the underlying principles of Learning Transfer;

- A trial-and-error approach is adopted to manage Learning Transfer.

Numerous learning transfer studies conducted in the past utilized a wide variety of instruments and measures (with questionable psychometric properties) to measure the transfer of learning (Holton, 2000). The aforementioned is also indicative of the problems the HRD Practitioner encounters in practice with regard to intervention effectiveness. The practitioner, on the one hand, is expected to implement high-impact learning 
interventions within the organisation but, on the other hand, has limited expertise and tools to facilitate the learning transfer process, and in addition, does not possess validated diagnostics that can be utilized to identify learning transfer obstacles. The implication follows that the learning transfer process cannot be managed efficiently in the organisation.

\section{TABLE 1}

\section{FACTOR INFLUENCING THE EFFECTIVENESS OF LEARNING TRANSFER}

\begin{tabular}{|c|c|c|}
\hline Factor & Variable & Description \\
\hline Learner/team & $\begin{array}{l}\text { - Adult learning principles } \\
\text { (Knowles, 1984; Knowles, } \\
\text { Holton, Swanson, 1998) } \\
\text { - Training motivation } \\
\text { (Facteau et al 1995; Warr } \\
\text { and Bunce 1995) } \\
\text { - Self-concept (Mink et al. } \\
\text { 1994; Knowles 1984) } \\
\text { - Learning motivation } \\
\text { (Mathieu et al. 1992; } \\
\text { Baldwin et al. 1991) } \\
\text { - Ability (Wexley en } \\
\text { Latham 1981) } \\
\text { - Attitude ( Ford en Noe } \\
\text { 1987) } \\
\text { - Self-efficacy (Gist et al. } \\
\text { 1991) } \\
\text { - Ability to receive } \\
\text { feedback (Knowles 1984) } \\
\text { - Post-training } \\
\text { maintenance (Gist et al. } \\
\text { 1990) } \\
\text { - Team learning conditions } \\
\text { and processes (Watkins } \\
\text { and Marsick 1993; Kasl et al. } \\
\text { 1995) } \\
\text { - Group support (Joubert } \\
\text { and Steyn 1984, Watkins } \\
\text { and Marsick 1993) }\end{array}$ & $\begin{array}{l}\text { Intra-personal processes } \\
\text { refer to character traits } \\
\text { unique to the individual and } \\
\text { that could influence the } \\
\text { effectiveness of an } \\
\text { intervention. The individual } \\
\text { learner does not function in } \\
\text { a vacuum, but forms part of } \\
\text { a greater system. This } \\
\text { implies that the interaction } \\
\text { process between the } \\
\text { individual and the greater } \\
\text { system results in reciprocal } \\
\text { influencing that should be } \\
\text { taken into account during } \\
\text { the evaluation process. }\end{array}$ \\
\hline $\begin{array}{l}\text { Work } \\
\text { environment }\end{array}$ & $\begin{array}{l}\text { - Work environmental } \\
\text { factors (Baldwin en } \\
\text { Ford 1988; Rouiller en } \\
\text { Goldstein 1993; Xiao 1996; } \\
\text { Ford en Weissbein 1997) } \\
\text { - Culture (Marquardt and } \\
\text { Engel 1993; Veldsman } \\
\text { 1998;) } \\
\text { - Management support } \\
\text { (Brinkerhoff and } \\
\text { Montesino 1995) }\end{array}$ & $\begin{array}{l}\text { In order to have an impact } \\
\text { within the organization, the } \\
\text { learner must apply newly } \\
\text { acquired knowledge, skills } \\
\text { and attitudes in the } \\
\text { workplace. Critical factors } \\
\text { for intervention success are } \\
\text { work environment aspects } \\
\text { such as support, learning } \\
\text { transfer climate and the } \\
\text { opportunity to apply new } \\
\text { skills. }\end{array}$ \\
\hline
\end{tabular}

The effectiveness of an intervention is influenced by a variety of factors over which the practitioner has little or no control. These factors should thus be taken into account during the evaluation process.

Learning event Applicability of The effect of the previously intervention; Needs analysis mentioned processes on processes; design; intervention effectiveness is implementation and well known and researched. evaluation practices Therefore, the inclusion of (Sullivan et al. 1990; these factors in the Brinkerhoff 1987; Broad and evaluation process is Newstrom 1992 ) instrumental in determining intervention effectiveness.

Most current models of transfer (Ford \& Weisbein, 1997; Rouiller $\&$ Goldstein, 1993) regard the workplace climate for transfer as an important variable that may impact on intervention effectiveness. In this regard Rouiller and Goldstein (1993, p. 379) conceptualise transfer climate as "... practices and procedures used in an organisation that connote or signal to people what is important". This relates to individual and group perceptions and interpretation of conditions and processes in the organisation that may inhibit or facilitate transfer. Arguing that the construct Transfer Climate is only one set of factors that influence transfer, Holton et al (2000) use the concept Transfer System and define it as all the factors in the person, training and organisation that influence transfer of learning to job performance. The concept Transfer System is therefore a broader construct than Transfer Climate but includes all factors traditionally referred to as Transfer Climate. Building on his evaluation approach (Holton, 1996), the Transfer Systems Approach (Figure 1) describes a subset of this evaluation approach namely, the transfer of learning to individual, group and organisational performance. The model hypothesises that HRD outcomes are a function of both ability/ enabling elements and motivation and environmental influences (Noe, 1986) at three outcome levels namely learning, individual performance and organisational performance (Holton, 2000).

The outcomes are respectively defined as the achievement of learning outcomes desired in an HRD intervention, change in individual performance as a result of the learning being applied in the job, and results as a consequence of the change in individual behaviour (Holton 1996). Secondary influences are

\begin{tabular}{|c|c|c|c|}
\hline Secondary influences & $\begin{array}{l}\text { Performance self-efficacy } \\
\text { Learner readiness }\end{array}$ & & \\
\hline Motivation & $\begin{array}{l}\text { Motivation to transfer } \\
\text { Transfer effort-performance } \\
\text { Performance outcomes }\end{array}$ & & \\
\hline Environment & & $\begin{array}{l}\text { Feedback } \\
\text { Peer support } \\
\text { Supervisor support } \\
\text { Openess to change }\end{array}$ & $\begin{array}{l}\text { Personal outcomes - } \\
\text { positive } \\
\text { Personal outcomes - } \\
\text { negative } \\
\text { Supervsior sanctions }\end{array}$ \\
\hline Outcomes & Learning & $\begin{array}{l}\text { Individual } \\
\text { performance }\end{array}$ & $\begin{array}{l}\text { Organisational } \\
\text { performance }\end{array}$ \\
\hline $\begin{array}{l}\text { Ability/ Enabling } \\
\text { elements }\end{array}$ & & $\begin{array}{l}\text { Content validity } \\
\text { Transfer design } \\
\text { Personal capacity for } \\
\text { transfer } \\
\text { Opportunity to use }\end{array}$ & \\
\hline
\end{tabular}


also included, especially those that affect motivation. Variables such as self-efficacy and learner readiness serve as examples in this regard. It is clear that the Learning Transfer System comprises four aspects (along with variables indicated in Figure 1), namely ability, motivational elements, the work environment and secondary influences. This is also indicative of mechanisms that should be measured and managed effectively in the learning transfer process in order to achieve intervention effectiveness. The identified variables are operationalized in Table 2 .

TABLE 2

DESCRIPTION OF VARIABLES

\begin{tabular}{ll}
\hline Variable & Description \\
\hline $\begin{array}{l}\text { Learner } \\
\text { Character- }\end{array}$ & Learner Rea \\
istics & \\
& \\
& \\
& Performance \\
& Self-Efficac
\end{tabular}

Motivation Motivation to Transfer Learning

Transfer Effort Performance Expectations

Performance Outcomes Expectations

Work en- Feedback/ vironment Performance Coaching

Supervisor/ Manager Support

Supervisor/Manager Sanctions
The degree to which the individual had the opportunity to provide input prior to the training, knew what to expect during the training, and understood how training related to job-related development and work performance.

The extent to which individuals feel confident and self-assured about applying new abilities in their jobs, and can overcome obstacles that hinder the use of new knowledge and skills.

The extent to which individuals are motivated to utilise learning in their work. This includes the degree to which individuals feel equipped to perform plan to use new skills and knowledge, and believe new skills will help them to perform on-the-job more effectively.

The extent to which individuals believe that applying skills and knowledge learned in training will improve their performance. This includes whether an individual believes that investing effort in utilising new skills has made a difference in the past or will affect future productivity and effectiveness.

The extent to which individuals believe the application of skills and knowledge learned in training will lead to desired recognition. This includes the extent to which organisations demonstrate the link between development, performance, and recognition; clearly articulate performance expectations, recognise individuals when they do well, reward individuals for effective and improved performance, and create an environment in which individuals feel good about performing well.

The extent to which individuals receive constructive input, assistance, and feedback from people in their work environment (peers, employees, $\mathrm{c}$ olleagues, managers, etc..) when applying new abilities or attempting to improve work performance. Feedback may be formal or informal cues from the workplace.

This includes managers' involvement in clarifying performance expectations after training, identifying opportunities to apply new skills and knowledge, setting realistic goals based on training, working with individuals on problems encountered while applying new skills, and providing feedback when individuals successfully apply new abilities.

This includes the extent to which managers oppose the use of new skills and knowledge, use techniques different from those taught in training, do not assist individuals in identifying opportunities to apply new skills and knowledge, or provide inadequate or negative feedback when individuals successfully apply learning on-the-job.
Peer Support

This includes the degree to which peers mutually identify and implement opportunities to apply skills and knowledge learned in training, encourage the use of or expect the application of new skills, display patience with difficulties associated with applying new skills, or demonstrate appreciation for the use of new skills

Resistance/openness This includes the work groups to Change resistance to change, willingness to invest energy in change, and the degree of support provided to individuals who use techniques learned in training.

Personal Outcomes - Positive outcomes include increased Positive productivity and work effectiveness, increased personal satisfaction, additional respect, a salary increase or reward, the opportunity to further career development plans and the opportunity to advance in the organisation.

Personal Outcomes - Negative outcomes include reprimands, Negative. penalties, peer resentment, too much new work and the likelihood of not getting a raise if newly acquired skills are utilised.

Ability/ Opportunity to This includes an organisation providing enabling Use Learning individuals with opportunities to apply new skills, resources needed to use new skills (equipment, information, materials, supplies) and adequate financial and human resources.

Personal Capacity This factor addresses the extent to which for Transfer individuals' work load, schedule, personal energy, and stress-levels facilitate or inhibit the application of new learning on-the-job.

Perceived Content This factor addresses the degree to Validity which the skills and knowledge taught are similar to performance expectations as well as what the individual needs to perform more effectively. It also addresses the extent to which instructional methods, aids, and equipment used in training are similar to those used in an individual's work environment.

Transfer Design The extent to which the training program is designed to clearly link learning with on-the-job performance through the use of clear examples, methods similar to the work environment, and activities and exercises that clearly demonstrate how to apply new knowledge and skills.

Problems in Learning Transfer

The following problems in learning transfer research have been identified by Holton (2000); Elangovan and Karakowsky (1999) and Ford and Weissbein (1997):

- The criterion problem of how training transfer is defined and operationalised and when it has to be measured;

- Prior research has often focused on the learning component of training rather than specifically examining the issue of transfer;

- Previous studies have focused primarily on issues concerning training design factors, especially the appropriateness of various instructional methods;

- There is a lack of attempts to conceptualise and operationalise work environment factors that can influence transfer;

- The majority of studies on trainee characteristics have focused on a narrow range of variables. There is also a lack of conceptual models to drive the choice of which trainee characteristics should be examined for their impact on transfer;

- A variety of instruments and measures have been used with questionable or unknown psychometric properties. 
Furthermore, many studies use low complexity methods to examine the generalisability of results from training design studies;

- Most evaluation efforts focus on reaction and learning rather than taking cognizance of factors influencing intervention effectiveness (Alliger \& Janak, 1989; Alliger, Tannenbaum, Bennett, Traver \& Shotland (1997):

- Practitioners usually adopt a trial-and-error approach for managing transfer.

- The nature of the tasks studied involve short-term, simple motor tasks and memory-skills training.

Concurring with the above, Holton and Baldwin (2000) are of the opinion that most research is not action-orientated in the sense that most researchers have stopped at the point of identifying, describing or measuring factors that may influence transfer, without investigating how these factors might be effectively managed. Furthermore, the lack of a prescriptive, action-orientated focus characterises much of the academic literature and reflects conservatism and reluctance to go beyond the data (Holton, 2000). The aforementioned is also indicative of problems the HRD Practitioner has to face. On the one hand, a multitude of variables that could influence intervention effectiveness are presented to the HRD Practitioner, yet on the other hand no solutions have been offered to deal with the identified problems.

Without validated scales, the chance for substantive misspecification of models, misinterpretation of findings, and measurement error is significantly increased. The lack of a commonly accepted measurement tool makes it difficult to get a clear picture of the relationship between personal, training environment and climate variables and transfer. Attempting to address the mentioned problems, a conceptual learning transfer system was established (Holton, 1996; 2000) and a diagnostic instrument, "Learning Transfer System Inventory" (LTSI), (comprising 16 factors and 89 items) compiled. Holton (2000) initially identified nine factors by means of factor analysis. The LTSI is based on the theoretical framework of the HRD Research and Evaluation Model (Figure 2) as conceptualized by Holton (Holton, 1996).

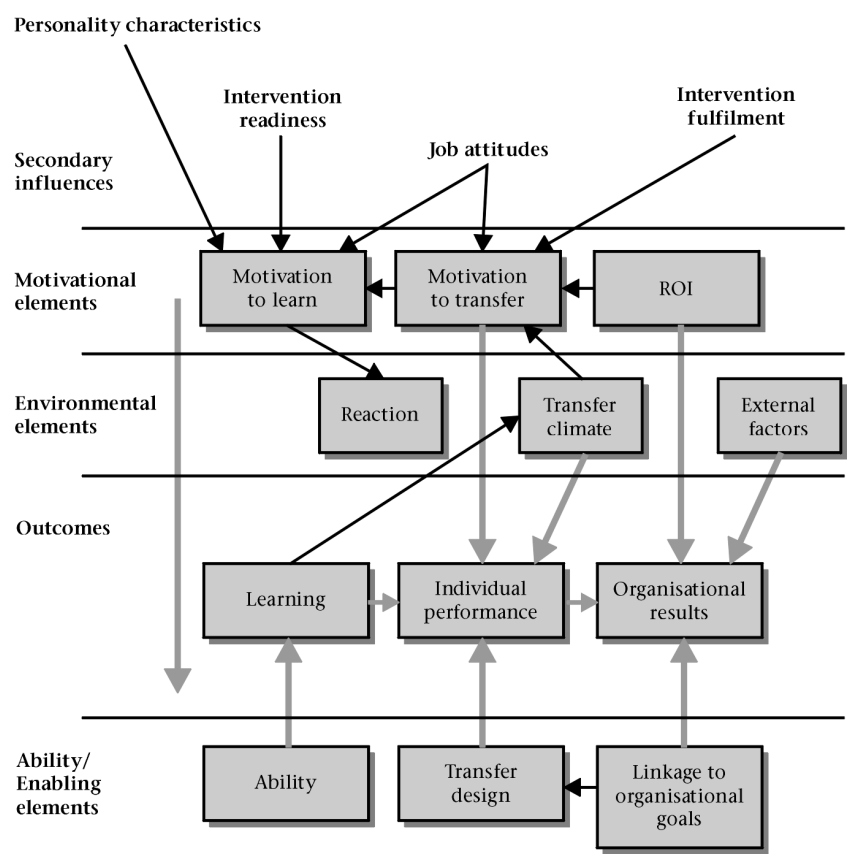

Figure 2: Conceptual evaluation approach (Holton 1996)

As already indicated, the LTSI model can be regarded as a subset of the HRD Research and Evaluation Model and the model theorizes that HRD outcomes can be regarded as a function of ability, motivation and environmental influences (Noe and Schmitt,
1986) at three outcomes levels namely learning, individual performance and organizational performance (Holton, 1996, 2000). The Holton (1996) Evaluation Approach also includes secondary influences (e.g. intervention readiness, work attitudes, personality characteristics and intervention fulfilment) that may impact on intervention effectiveness. In line with this approach, the LTSI Model includes only two secondary factors that may influence motivation namely learner readiness and performance self-efficacy. In this regard learning readiness refers to the "need to prepare learners to participate in the learning experience" and performance self-efficacy refers to the belief held by learners that "the learning can be used to change their performance".

\section{Problem Statement}

The general problem examined in this study mainly centers on the measurement of learning transfer in the work environment in the South African context. As already indicated, despite the importance of learning and the transfer of learning to the work environment, the HRD field does not have a generally accepted measurement approach nor does it have clear concensus on the nomological network of factors affecting transfer of learning in the workplace. Holton, Bates, Seyler and Carvalho (1997) argue in this regard that what should be an important goal for HRD research is the development of a valid and generalisable set of transfer system scales. Not only will an established set of transfer scales with validated constructs and known psychometric properties facilitate valid cross-study comparisons, but will also enhance practitioners' understanding of the learning transfer process.

Furthermore, previous evaluation approaches focus mainly on finding answers to the question "what was the intervention's contribution towards organisational effectiveness?" but exclude important variables that may impact on intervention effectiveness. Establishing a validated learning transfer scale should enable practitioners to find more answers concerning the "reason" why interventions are successful in certain contexts and unsuccessful in others. In this regard, Holton et al (2000) state that from a theoretical perspective, identifying and measuring dimensions of the work context that affect use of learned skills and behaviours provides a more complete conceptual framework of training effectiveness.

Against this background, the research problem in question is as follows:

- Will exploratory factor analysis of the Learning Transfer System Inventory (LTSI) result in an interpretable factor structure of latent transfer system constructs when applied within the South African context?

- From this, the following secondary objective was formulated:

- To validate the Learning Transfer System Inventory (LTSI) within South African context.

\section{RESEARCH DESIGN}

\section{Research approach}

This study is a quantitative study and a cross-sectional survey design was used to describe the information on the population collected. The study is also exploratory and descriptive as well as retrospective in nature (i.e. it was done on retrospective data). Elements of the research design are predetermined and in addition it is ex post facto and attempts to show causes and consequences after they have occurred.

\section{Research Methodology} Sample

The sample utilised in this study is a convenience sample of SA employees undergoing training and comprises all employees $(\mathrm{N}=240)$ of the Home Loan Processing Section of a well-known listed Banking Group in South Africa. The section is responsible for processing all home loans, including credit screening, data capturing of information and administrative loan management, for the Banking Group. The respondents are dispersed over five 
geographic areas in South Africa, namely Randburg, Pretoria, Bloemfontein, Durban and Cape Town. A total of 240 questionnaires were distributed of which 215 (90\%) were returned. The data was captured and converted into a data file. After filtering of the data based on criteria such as incompleteness and the giving of socially acceptable answers (see the following paragraph), the workable number of questionnaires was 177 , that is, $82 \%$ of the total number of returned questionnaires was usable. The large number of questionnaires considered unusable can be attributed to the following factors:

- Some respondents felt threatened when confronted with the organisation being evaluated, and in spite of assurances that all information would be treated confidentially, feared being victimised by the organisation. This was particularly true for sensitive questions related to the organisation itself where respondents simply failed to answer these questions.

- Some respondents gave socially acceptable responses. This indicates the extent to which respondents' answers to the questions did not reflect the intensity of their own experiences, but rather what they believed an acceptable response should be. Some questions were formulated in such a manner that socially acceptable responses could be identified through inspection.

\section{Measuring Instrument}

The items on the LTSI instrument are divided into two sections. The first section contains seventy-six items measuring eleven constructs, which represent factors affecting the specific training programme attended (Holton, 2000). Section 2 measures five constructs that are not programme-specific but represent general factors that may influence any training programme. Holton (2000) argues in this regard that these sixteen factors represent factors most commonly identified in transfer research and have been validated by construct validation studies.

\section{Research procedure}

Questionnaires were distributed electronically to the employees of the section. Prior to sending out the questionnaires, the Training Section of the Banking Group familiarized employees in each geographical area with the objectives of the investigation, the means of data collection and discussed the questionnaire's content with them. Respondents completed the questionnaires in hard copy in their own time and returned the completed questionnaires to the Training Section by internal mail. Hence, responses were anonymous.

Table 3 contains scale definitions, number of items and Cronbach Alpha Reliabilities. In addition to completing the 89 LTSI items (each measured on a 5-point Likert-type scale), respondents were also asked to provide background information including age, gender, qualification and years of service within the Banking Group and in their current job.

\section{Statistical Analysis}

Statistical analysis focused on the identification of latent variables of the LTSI by means of exploratory factor analysis and the estimation of the reliabilities (Cronbach Alpha) of the identified latent variables. The results of the 89-item questionnaire were subjected to both a first-order (factors rotated by means of Varimax rotation) and subsequent secondorder (factors rotated by means of Direct Obliman method) factor analysis. In both cases, factors were extracted using the Kaiser criterion (the number of eigenvalues greater than unity) and Principal Factor Analysis (PFA) was used.

Diagnostics included Bartlett's Test of Sphericity and the Kaiser Mayer Olkin (KMO) Measure of Sampling Adequacy (MSA). Bartlett's Test of Sphericity is a statistical test for the presence of correlations among variables. Hair, Anderson, Tatham \& Black (1998) say in this regard that the test provides the statistical probability that the correlation matrix has significant correlations among at least some of the variables. The KMO quantifies the degree of intercorrelations among the variables and the appropriateness or applicability of factor analysis. MSA values were also determined per item to determine whether the specific items should be used in the factor analysis. A cut-off point of 0,6 was used throughout. According to Hair et al. (1998) this measure can be interpreted with the following guidelines: .80 or above, meritorious; 0,70 or above, middling; .60 or above, mediocre; 0,50 or above, miserable; and below 0,50 unacceptable. It is also important to note that the MSA increases as (1) the sample size increases, (2) the average correlations increase, (3) the number of variables increases, or (4) the number of factors decreases.

TABLE 3

Scales and Cronbach Alpha reliabilities of the LSTI

Scale Name Scale Definition $\quad \begin{gathered}\text { Number of } \\ \text { items } \begin{array}{c}\text { Cronbach } \\ \text { alpha } \\ \text { reliabilities }\end{array}\end{gathered}$

Trainee Characteristics Scales

Learner Readiness The extent to which individuals are prepared to enter and participate in a training program.

Performance An individual's general belief

Self-Efficacy that they are able to change their performance when they want to.

Motivation Scales The direction, intensity and 4

Motivation to persistence of effort towards

Transfer Learning utilising in a work setting skills and knowledge learned in training.

Transfer Effort - The expectation that effort devoted 4

Performance to transferring learning will lead

Expectations to changes in job performance.

Performance - The expectation that changes in 5

Outcomes job performance will lead to

Expectations outcomes valued by the individual.

Work Environment Scales

Feedback/ Formal and informal indicators

Performance from an organisation about an

Coaching individuals job performance

Supervisor/ The extent to which managers

Manager Support support and reinforce the use of learning on-the-job.

Supervisor/

Manager

The extent to which individuals

Sanctions perceive negative responses from managers when applying skills

learned in training.

Peer Support

The extent to which peers reinforce and support use of learning on-the-job.

Resistance/ The extent to which prevailing openness to Change group norms are perceived by individuals to resist or discourage the use of skills and knowledge acquired in training.

Personal The degree to which applying

Outcomes-

Positive training on-the-job leads to outcomes that are positive for the individual.

Personal

The extent to which individuals 4

4

4

Outcomes believe that applying skills and knowledge learned in training will lead to outcomes that are negative.

Ability Scales

Opportunity to

The extent to which trainees are and tasks on-the-job enabling them to use the skills taught in training.

Personal

Capacity for

The extent to which individuals

have the time, energy and mental space in their work lives to make changes required to transfer learning to the job.

Perceived The extent to which the trainees 5

Content Validity judge the training content to accurately reflect job requirements.

Transfer Design The extent to which training has 4 been designed to give trainees the ability to transfer learning to job application and the training instructions match the job requirements. 
RESULTS

TABLE 4

NUMBER OF MEN AND WOMEN COMPLETING THE LTSI

\begin{tabular}{llcccc}
\hline & & Frequency & Percent & $\begin{array}{c}\text { Valid } \\
\text { Percent }\end{array}$ & $\begin{array}{c}\text { Cumulative } \\
\text { Percent }\end{array}$ \\
\hline Valid & Males & 47 & 21,3 & 21,6 & 21,6 \\
& Female & 171 & 77,4 & 78,4 & 100,0 \\
& Total & 218 & 98,6 & 100,0 & \\
\multirow{2}{*}{ Missing } & System & 3 & 1,4 & & \\
\multirow{2}{*}{ Total } & & 221 & 100,0 & & \\
\hline
\end{tabular}

Table 4 indicates that 171 woman $(78,4 \%)$ and 47 males $(21,6 \%)$ completed the LTSI. Due to incomplete information, 3 questionnaires were not used in the data analysis process.

TABLE 5

Age distribution OF RESPONDENTS

\begin{tabular}{llcccc}
\hline & & Frequency & Percent & $\begin{array}{c}\text { Valid } \\
\text { Percent }\end{array}$ & $\begin{array}{c}\text { Cumulative } \\
\text { Percent }\end{array}$ \\
\hline Valid & Up to 24 years & 67 & 30,3 & 31,3 & 31,3 \\
& $25-29$ years & 52 & 23,5 & 24,3 & 55,6 \\
& 30 - 39 years & 53 & 24,0 & 24,8 & 80,4 \\
& 40 years and older & 42 & 19,0 & 19,6 & 100,0 \\
& Total & 214 & 96,8 & 100,0 & \\
Missing & System & 7 & 3,2 & & \\
Total & & 221 & 100,0 & & \\
\hline
\end{tabular}

The age distribution of the respondents is shown in Table 5 . The majority of respondents $(55,6 \%)$ indicated being younger than 30 years old; $24,8 \%$ between 30 and 39 years old and $19,6 \%$ were 40 years or older. Due to incomplete information, 7 questionnaires were not used in the data analysis process.

TABLE 6

WORK EXPERIENCE OF RESPONDENTS IN BANKING GROUP AND CURRENT POSITION

\begin{tabular}{|c|c|c|c|}
\hline \multirow[t]{2}{*}{$\begin{array}{l}\text { Length of service with } \\
\text { Banking Group }\end{array}$} & \multicolumn{2}{|c|}{$\begin{array}{l}\text { Length of service in current } \\
\text { position }\end{array}$} & Total \\
\hline & \multicolumn{2}{|c|}{ Less than 5 years } & 5 years or more \\
\hline Less than 5 years & 119 & & $119(58,3 \%)$ \\
\hline 5 years or more & 73 & 12 & $85(41,7 \%)$ \\
\hline Total & $192(94,1 \%)$ & $12(5,9)$ & 204 \\
\hline
\end{tabular}

As far as work experience is concerned, it appears from Table 6 that the majority of respondents $(94,1 \%)$ have relatively limited experience $(<5$ years) in their current positions while $58.3 \%$ have less than 5 years experience with the Banking Group. Only 12 respondents (14.12\%) of the 85 respondents with 5 years or more experience with the Banking Group also have 5 years or more experience in their current positions.

With regard to the language distribution of the respondents (see Table 7), it appears that the majority of the respondents $(51,6 \%)$ are Afrikaans-speaking. On the other hand, $31,2 \%$ of the respondents are English-speaking and only 17,2\% of the respondents have a Black (African) language as mother tongue.
TABLE 7

Prefered language of respondents

\begin{tabular}{llcccc}
\hline & & Frequency & Percent & $\begin{array}{c}\text { Valid } \\
\text { Percent }\end{array}$ & $\begin{array}{c}\text { Cumulative } \\
\text { Percent }\end{array}$ \\
\hline Valid & Afrikaans & 114 & 51,6 & 51,6 & 51,6 \\
& English & 69 & 31,2 & 31,2 & 82,8 \\
& African Language & 38 & 17,2 & 17,2 & 100,0 \\
Total & 221 & 100,0 & 100,0 & \\
\hline
\end{tabular}

TABLE 8

Formal EDUCATION

\begin{tabular}{llcccc}
\hline & & Frequency & Percent & $\begin{array}{c}\text { Valid } \\
\text { Percent }\end{array}$ & $\begin{array}{c}\text { Cumulative } \\
\text { Percent }\end{array}$ \\
\hline Valid & Less than grade 12 & 40 & 18,1 & 21,5 & 21,5 \\
& Diploma or B-Degree & 61 & 27,6 & 32,8 & 54,3 \\
& Other & 85 & 38,5 & 45,7 & 100,0 \\
& Total & 186 & 84,2 & 100,0 & \\
\multirow{2}{*}{ Missing } & System & 35 & 15,8 & & \\
Total & & 221 & 100,0 & & \\
\hline
\end{tabular}

Of the 186 respondents answering the question related to their highest academic qualification, 21,5\% indicated having a qualification lower than Grade 12 and 32,6\% indicated having a post-school diploma or degree. A high percentage of respondents $(45,7 \%)$ indicated having another qualification than that listed in the questionnaire.

TABLE 9

RELIABILITY COEFFICIENTS OF THE LTSI

\begin{tabular}{|c|c|c|c|}
\hline Factor & Items & $\begin{array}{l}\text { Number } \\
\text { of items }\end{array}$ & $\begin{array}{l}\text { Cronbach } \\
\text { Alpha }\end{array}$ \\
\hline 1 & 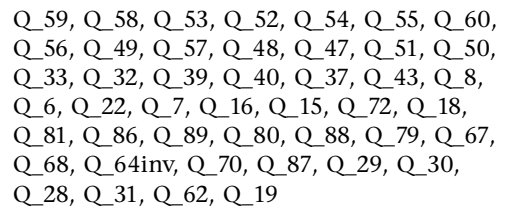 & 45 & 0,9640 \\
\hline 2 & 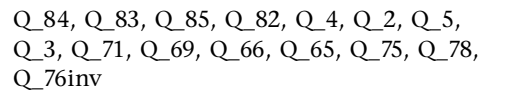 & 15 & 0,8828 \\
\hline 3 & $\begin{array}{l}\text { Q } 41 \text {, Q } 464, \text { Q } 42, \text { Q } 45 \text {, Q } 34, \text { Q } 27, \text { Q 38, } \\
\text { Q } 35, \text { Q } 36, \text { Q } 12, \text { Q } 11, \text { Q } 63, \text { Q } 26\end{array}$ & 13 & 0,8290 \\
\hline 4 & Q 23, Q 24, Q 25, Q 13, Q 9 & 5 & 0,5093 \\
\hline
\end{tabular}

The items of the LSTI (89) were subjected to a First-Order Factor Analysis using Principal Factor Analysis. Eleven of the 89 items were subsequently excluded from the initial factor analysis due to the MSA values for these items being less than 0,6 . The KMO statistic for the correlations among the remaining 78 questions was $0,857(>0,6)$ and Bartlett's test was significant (p-value $<0.001$ ) indicating that the correlation matrix can be factor analysed. The MSA values for all 78 items were larger than 0,6. Seventeen (17) first-order factors were extracted based on the Kaizer criterion, accounting for $71 \%$ of the variation in the original 78 items. An orthogonal rotation (Varimax) was used to improve interpretability of factors. The resulting 17 factors were subjected to a second-order factor analysis resulting in 4 factors according to the Kaizer criterion. To improve interpretability, an oblique rotation (Direct Oblimin) was used. Items having been reversed, (based on negative first-order factor loadings) appear 
with a postscript (inv) in Table 9. The reliabilities of the first three factors exceed 0,7 and are thus considered reliable. The reliability of factor 4 , consisting of 5 items only, is lower than 0,7 and cannot be considered reliable. Table 9 shows the items in each second order factor together with the reliabilities of these scales.

\section{DISCUSSION}

It could be argued that the relatively youthful age of the respondents holds certain advantages for the study in question. Given the changed world of work, the employees would be expected to be more amenable to acquiring new knowledge and applying skills in the workplace. The aforementioned makes the respondents an ideal target group for reporting on learning transfer and on the variables it influences. On the other hand, one could speculate that persons in the 50-59 years old age group $(4,2 \%)$ and the $60-69$ years old category $(, 9 \%)$ are at the end of their careers and, therefore, are less enthusiastic about learning and utilizing new skills.

An analysis of the items with the largest loading on Factor 1 indicates that these items are linked to activities directly encountered in the work environment, i.e. situational indicators. On scrutiny of the items, it is apparent that the following aspects are incorporated in the factor:

- The extent to which individuals believe the application of skills and knowledge learned in training will lead to the recognition they value. This includes the extent to which organisations demonstrate the link between development, performance, and recognition, clearly articulate performance expectations, recognise individuals when they do well, reward individuals for effective and improved performance, and create an environment in which individuals feel good about performing well.

- The extent to which individuals receive constructive input, assistance, and feedback from people in their work environment (peers, employees, colleagues, managers) when applying new abilities or attempting to improve work performance. Feedback may be formal or informal cues from the workplace.

- The extent to which managers are involved in clarifying performance expectations after training, identifying opportunities to apply new skills and knowledge, setting realistic goals based on training, working with individuals on problems encountered while applying new skills, and providing feedback when individuals successfully apply new abilities.

- The degree to which peers mutually identify and implement opportunities to apply skills and knowledge learned in training, encourage the use of or expect the application of new skills, display patience with difficulties associated with applying new skills, or demonstrate appreciation for the use of new skills;

- The extent to which training has positive outcomes, including increased productivity and work effectiveness, increased personal satisfaction, additional respect, a salary increase or reward, the opportunity to further career development plans, or the opportunity to advance in the organisation.

- This extent to which the organisation provides individuals with opportunities to apply their proficiency and the financial and human resources (equipment, information, materials, supplies) to use new skills.

- The extent to which skills and knowledge taught are similar to performance expectations as well as what the individual needs to perform more effectively. It also addresses the extent to which instructional methods, aids, and equipment used in training are similar to those used in the individual's work environment.

In accordance with the view of Rouiller and Goldstein (1993), the items can be considered Situational Indicators (reminding learners of the training undergone or providing learners with the opportunity to use their skills and knowledge in the workplace). Factor 1 thus points to situational indicators encountered in the workplace.

While Factor 1 is linked to the indicators present in the work environment, Factor 2 refers mainly to the intra-personal processes as applicable to the learner. Closer scrutiny of the items in question indicate that this factor addresses the following aspects:

- The extent to which individuals feel confident and selfassured about applying new abilities in their jobs, and can overcome obstacles that hinder the use of new knowledge and skills.

- The extent to which individuals are motivated to utilize newly acquired learning in their work. This includes the degree to which individuals feel better able to perform, plan to use new skills and knowledge, and believe new skills will help them to perform more effectively on-the-job.

- The extent to which individuals believe that applying skills and knowledge learned in training will improve their performance. This includes whether an individual believes that investing effort in utilizing new skills has made a difference in the past or will affect future productivity and effectiveness.

- The extent to which the work group accepts change, is willing to invest energy in changing, and supports individuals who use techniques learned in training.

Van Zyl and Lessing (1992:7) state that "these characteristics are personal and unique to the individual and reflect the individual's intrinsic perception". In that the foregoing is indicative of characteristics that can be regarded as being personal and unique to the individual and which reflect the individual's intrinsic perception, the factor is classified as Intra-Personal Indicators and Motivation.

From a thorough study of items related to Factor 3 and concurring with Rouiller and Goldstein (1993) as well as with Holton, Bates, Seyler \& Carvalho (1997), it is apparent that the items could be considered as Consequential and Managerial Indicators. This is regarded by Holton et. al (1997) as on-the-job outcomes that affect the extent to which training is transferred. This factor thus emphasizes the role of the supervisor/manager. One could speculate that the extent to which the supervisor creates a climate in which the learner experiences low levels of stress, has a reasonable workload and is empowered, would exercise an important influence on learning transfer. It seems appropriate to classify the Factor as Consequential and Managerial indicators.

In spite of Factor 4 having a relatively low level of reliability $(0,5093)$ it was decided to retain this factor since previous studies (Smith-Jentsch, Jentsch, Payne \& Salas 1996) emphasize the importance of pre-training experiences and the influence they have on learning transfer. Factor 4 refers, among others, to aspects such as the degree to which the individual had the opportunity to provide input prior to the training, knew what to expect during the training, and understood how training was related to job-related development and work performance. Moreover, it is important that the supervisor fully clarifies mutual expectations concerning the utilisation of newly acquired knowledge and so forth, prior to commencing with the training. It was decided to classify this factor as Learner Orientation Indicators.

The four factors, namely Situational Indicators, IntraPersonal indicators, Consequential and Managerial Indicators and Learner Orientation Indicators denote those factors that inhibit or facilitate learning transfer. It is anticipated that organisations achieving high scores for these factors will be capable of facilitating effective learning transfer from the classroom to the workplace. 
The four (second order) factors identifiend in this exploratory study of the South African situation relate to the original factors (see table 3) of the LTSI. Situational Factors (Factor 1), which are encountered in the work environment, remind learners of the training they have undergone and can have a facilitating or inhibiting effect on learning transfer. If the initial factors of the LTSI (see Table 3) are analyzed by means of inspection, it is apparent that the following original scales of the LTSI are related to Factor 1 (see Table 10):

\section{TABLE 10}

COMPARISON OF LTSI WITH FACTOR 1

\begin{tabular}{ll}
\hline Factor 1 & LTSI scales \\
\hline Situational Indicators & - Performance-Outcomes Expectations \\
& - Feedback/Performance/Coaching \\
& - Peer support \\
& - Personal outcomes - positive \\
& - Perceived content validity \\
& - Transfer design \\
\hline
\end{tabular}

One could also speculate that Factor 1 (Situational Indicators) is probably associated with learning transfer climate as maintained by Rouiller and Goldstein (1993). The previous discussion of work environment factors indicated that work environment factors such as support, learning transfer climate and opportunity to apply acquired knowledge, can be regarded as being critical to learning transfer. In summing up and concurring with the opinion of Holton (2000), Factor 1 probably refers to the learner's perception of the work environment and this influences the extent to which a learner will or will not utilize learned skills in the work environment. Tracy, Tannenbaum and Kavanagh (1995), as well as Xiao (1996), have found that the transfer climate has an important influence on the learner's motivation to apply acquired knowledge and skills in the workplace. The learning transfer climate can furthermore act as a mediator between the organisational context and the learner's attitude towards and behaviour at work.

Should the initial factors of the LTSI (see Table 3 ) be analyzed by means of inspection, it is apparent that the following original scales of the LTSI are related to Factor 2 (see Table 11):

TABLE 11

COMPARISON OF LTSI WITH FACTOR 2

\begin{tabular}{ll}
\hline Factor 2 & LTSI scales \\
\hline Intra-personal Indicators & • Performance- Self-efficacy \\
& - Motivation to transfer learning \\
& Transfer Effort- Performance expectations
\end{tabular}

On analyzing the scales of the LTSI (see Table 3) by means of inspection, it is apparent that the following are related to Factor 3 (see Table 12):

TABLE 12

COMPARISON OF LTSI WITH FACTOR 3

\begin{tabular}{ll}
\hline Factor 3 & LTSI scales \\
\hline Consequential and & $\bullet$ Supervisor/Manager sanctions \\
Managerial Indicators & $\bullet$ Personal capacity for transfer Motivation \\
& to transfer learning \\
\hline
\end{tabular}

By analysis of initial scales of the LTSI (see Table 3) by means of inspection, the following original factors seem to be related to Factor 4 (see Table 13):
TABLE 13

COMPARISON OF THE LTSI WITH FACTOR 4

\begin{tabular}{ll}
\hline Factor 4 & LTSI scales \\
\hline Learning orientation indicator & $\bullet$ Learner readiness \\
& $\bullet$ Personal outcomes - negative \\
\hline
\end{tabular}

The results provide an indication of the factor structure of the LTSI in the South African. It was shown that, for this sample 17 factors were initially extracted by means of a Principle Factor Analysis. Moreover, the second-order factor analysis extracted four factors which were classified as follows:

Factor 1: Situational Indicators;

Factor 2: Intra-personal Indicators and Motivation;

Factor 3: Consequential and Managerial Indicators;

Factor 4: Learning Orientation Indicators.

It was also indicated that the identified four Second-Order factors relate to the original scales identified for the LTSI (Table 3). It was further indicated that constructs that could be regarded as indicative of learning transfer climate (Rouiller and Goldstein 1993) reflect strongly in both Factor 1 and Factor 3. This can probably be ascribed to the fact that the original items of Rouiller and Goldstein's (1993) Learning Transfer Climate Questionnaire were included in the LTSI.

From the results it appears that the factor structure of the LTSI, as revealed by means of the exploratory approach, appears differently in the South African context. Moreover, it was also indicated that the singular factor structure is interpretable in a changed context. It is important to note that because of culture and diversity differences between the American and South African contexts, a deliberate decision was made to choose the Exploratory Approach as well as determining the factor structure from the mentioned paradigm.

Figure 1, the Conceptual Model of Transfer, could probably be adapted according to the results in question as indicated in Figure 3. The adapted model hypothesizes that HRD outcomes are a function of ability/enabling elements, individual characteristics and environmental influences at three outcome levels namely learning, individual performance and organisational performance (Holton 2000). The outcomes are respectively defined as the achievement of learning outcomes desired in an HRD intervention, change in individual performance as a result of the learning being applied in the job and results as a consequence of the change in individual behaviour (Holton 1996).

Figure 3 is furthermore indicative of those factors that an organisation should include in its learning transfer system and which should be managed as such. It is, however, important to note that the preceding should be regarded as an integral part of the training cycle. The implication is that aspects such as analysis, design, implementation, presentation and evaluation should form an integral part of the learning transfer system. The mentioned factors, as well as the components of the training cycle, could be considered as critical leverage points that organisations could utilize to manage learning transfer effectively. A brief explanation of practice-directed recommendations that embody the preceding information ensues.

In the previous discussion the problems related to learning transfer and indicated that no generally accepted measuring instrument exists which can effectively measure variables that influence learning transfer. Moreover, existing instruments are utilized and validated in contexts that do not reflect the unique demands and distinctiveness of the South African context. Against this background the LTSI has been applied to the South African context and the results can be applied and used in practice as follows: 


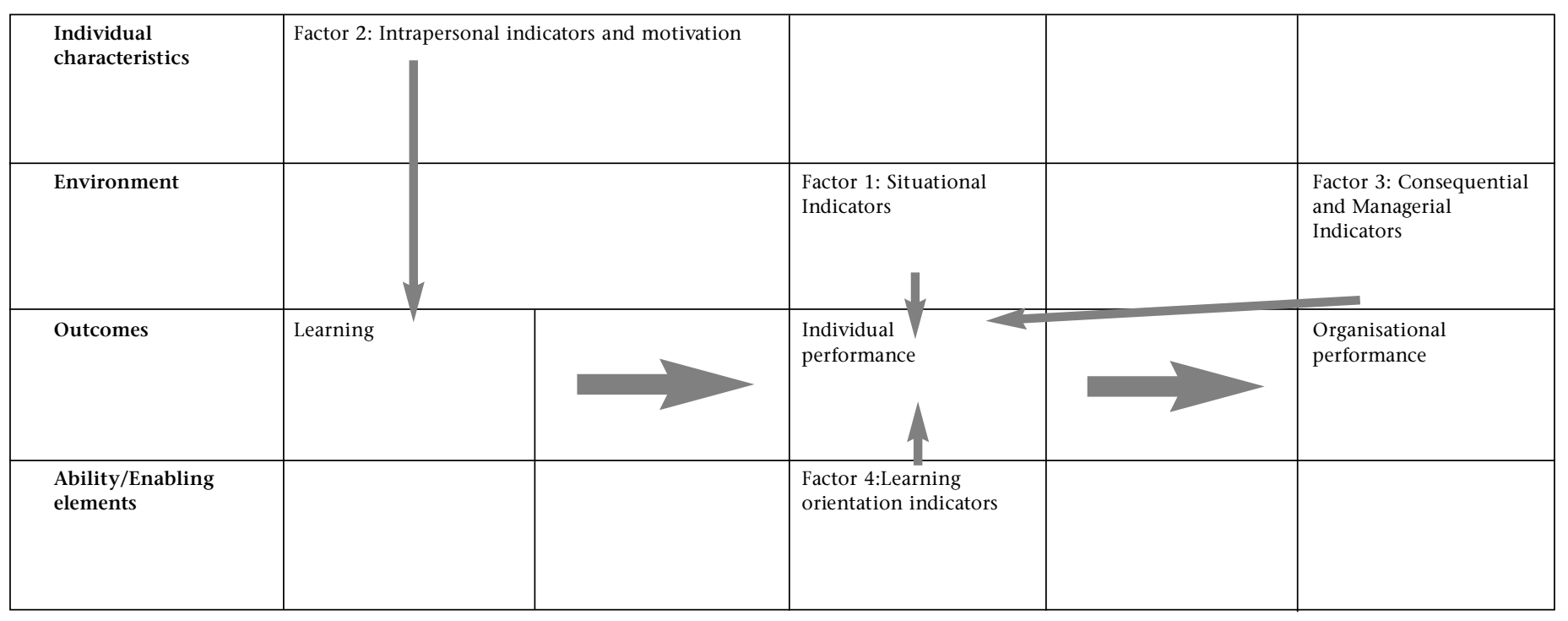

Figure 3: Adapted model

- The questionnaire can enable an organisation to identify those variables that inhibit learning transfer (within South African context) and to compile an organisationally-specific learning transfer system in accordance with the results. The foregoing can serve as management mechanisms to manage learning transfer effectively;

- The importance of creating a learning transfer climate in the work environment is emphasized by the results and can be utilized in practical terms as follows:

- Deliberately create opportunities where learners are able to utilize their newly acquired skills in the work place;

- Before any training commences the learner must be orientated about the nature, content and practical application of knowledge and skills to be acquired during training;

- Support learners by providing resources, material and equipment that will enable them to utilize acquired knowledge and skills;

- Ensure that there is congruence between the manner in which training occurs, the resources used and the work environment;

- The content of all training programmes should reflect workrelated examples so that learners can make the connection between what is learnt and what actually takes place in the work place;

- Further to the above, the organisation should create a performance-directed climate and indicate to the learners the link between learning, performance and reward;

- Feedback should be given to learners formally and informally, and recognition should be given if newly acquired knowledge has been applied;

- Supervisors/managers should be considered as important stakeholders in the training cycle and their commitment to the training process should be obtained;

- Supervisors/managers should clarify their expectations of the training with the learners and should compile a Skills Application Strategy (while cooperating with the learner). This will offer a frame of reference to the learner to use for applying acquired knowledge and skills;

- Although management should clarify their expectations with the learner (regarding the application of knowledge and skills), it is important to determine some form of sanction should the learner not apply the knowledge and skills learnt;

- The working group should be regarded as an important learning transfer mechanism and should be implemented as such. This can manifest in various ways, but attention should be paid to aspects such as group support, group learning, and also sanctionable behaviour if knowledge and skills are not applied.
From the above discussion there are clearly a multitude of interventions that can be launched to facilitate learning transfer from the classroom to the work environment. It is important however, to ensure congruence exists between organisational culture and the particular type of learning transfer intervention. This is also indicative of the importance of accommodating unique contextual demands purposefully and effectively in the compilation of a learning transfer system.

Studying Figure 11 it is clear that the Conceptual Model does omit critical variables. Noe (2000: 362 ) argues in this regard that the conceptual model omits:

- Dispositional factors such as anxiety and the "big five" personality factors;

- Career, job attitudes, job involvement.

- Organisational commitment;

- Self-assessment of individual strengths and weaknesses;

- Adequate assessment of trainee and design characteristics

Despite the identified deficiencies, it can be argued that including all possible variables would dramatically reduce the utility value of the approach (particularly in practice). Aspects such as the period of time it takes to implement the approach and costs related to the investigation, serve as examples in this regard. Holton et al. (2000) state that the LTSI is best utilized as a "pulsetaking" diagnostic tool in an Action-Research Approach in organisational development. Furthermore, the model is systematic in nature and the authors have paid rigorous attention to internal and external validity of included constructs. Linking to the previous statement, the model builds and expands on existing transfer of theory and research. Due to the fact that the sample is a convenience sample of employees in SA undergoing training, generalisation should be considered tentative and further investigation is necessary to verify the factor structure of the LTSI in the SA context. Questionnaires were sent electronically to the respondents, and among the disadvantages of dissemination in this way, is the lack of interest by the respondents and the lack of control over them regarding the completion of the questionnaires.

\section{REFERENCES}

Alliger, G.M. \& Janak, E. A. (1989). Kirkpatrick's levels of training criteria: thirty years later. Personnel Psychology, 42 (2), 331-341.

Alliger, G.M., Tannenbaum, S.I., Bennett, W., Traver, H. \& Shotland, A. (1997). A meta-analysis of the relations among training criteria. Personnel Psychology, 50 (1), 341-358.

Baldwin, T.T. \& Ford, J.K. (1988). Transfer of training; a review and directions for future research. Personnel Psychology, 41, $63-105$. 
Baldwin, T.T., Majuka, R.J. \& Loher, B.T. (1991). The perils of participation: the effects of choice on training motivation and learning. Personnel Psychology, 44, 51-67.

Brinkerhoff, R.O. \& Montesino, M.U. (1995). Partnerships for training transfer: lessons from a corporate study. Human Resource Development Quarterly, 6 (3), 263-274.

Brinkerhoff, R.O. (1987). Achieving results from training. San Francisco, C.A.: Jossey-Bass.

Broad, M.L. \& Newstrom, J.W. (1992). Transfer of training: Actionpacked strategies to ensure high payoff from training investments. Reading, MA: Addison-Wesley.

Elangovan AR \& Karakowsky L (1999) The role of trainee and environmental factors in transfer of training: an exploratory framework. Leadership and Organizational Development, 20 (5): 268- 275

Facteau, J.D., Dobbins, G.H., Russel, J.E.A., Ladd, R.T. \& Kudisch, J.D. (1995). The influence of general perceptions of the training environment on pre-training motivation and perceived training transfer. Journal of Management, 21 (1), $1-25$.

Ford JK \& Weissbein DA (1997) Transfer of training: An updated review and analysis Performance Improvement Quarterly, 10 (2), 22-41.

Gist, M.E., Bavetta, A.G. \& Stevens, C.K. (1990). Transfer training method: it's influence on skill generalization, skill repetition and performance level. Personnel Psychology, 43 (3), 501- 523.

Gist, M.E., Stevens, C.K. \& Bavetta, A.G. (1991). Effects of selfefficacy and post-training intervention on the acquisition and maintenance of complex interpersonal skills. Personnel Psychology, 44 (4), 837-861.

Holton EF \& Baldwin TT (2000) Making transfer happen: an action perspective on learning transfer systems. In Managing and Changing Learning Transfer Systems Adcances in Developing Human Resources, 8, 1-6.

Holton, E.F. (1996). The flawed four-level model. Human Resource Development Quarterly, 7, 5-19.

Holton, E.F. (2000). What is really wrong: Diagnosis for learning transfer system change. Advances in Developing Human Resources, 8, 7-22.

Holton, E.F., Bates, R., Seyler, D. \& Carvalho. (1997). Toward construct validation of of a transfer climate instrument. Human Resource Development Quarterly, 8, 95-113.

Joubert, D.D. \& Steyn, A.F. (1984). Groepsdinamika: 'n Inleiding tot die studie van klein groepe. Stellenbosch: UniversiteitsUitgewers en -Boekhandelaars (Edms.)Bpk.
Kasl, E., Marsick, V.J. \& Dechant, K. (1995). Teams as learners: A Research -based model of team learning stages, processes and conditions. Journal of Applied Behavioural Science.

Knowles, M.S. (1984). Andragogy in action: applying modern principles of adult learning. San Francisco, C.A.: Jossey-Bass.

Marquardt, M.J. \& Engel, D.W. (1993). Global Human Resource Development. Englewood Cliffs: Prentice-Hall Inc.

Mathieu, J.E., Tannenbaum, S.I. \& Sallas,E. (1992). Influences of individual and situational characteristics on measures of training effectiveness. Academy of Management Journal, 35, 828-847.

Mink, O.G., Mink, B.P., Downes, E.A., Owen, K.Q. (1994). Open Organizations: A Model for Effectiveness, Renewal, and Intelligent Change. San Francisco: Jossey-Bass Publishers

Noe, R.A. (1986). Trainees' attributes and attitudes: neglected influences on training effectiveness. Academy of Management Review, 11, 736-749.

Noe, R.A. \& Schmitt, N. (1986). The influence of trainee attitudes on training effectiveness: test of a model. Personnel Psychology, 39 (3), 497-523.

Rouiller, J.Z. \& Goldstein, I.L. (1993). The Relationship Between Organizational Transfer Climate and Positive Transfer of Training. Human Resource Development Quarterly, 4 (4), 377-390.

Senge, P. 1990. The fifth discipline: The art and practice of the learning organization. New York: Nicholas Brealy.

Smith-Jentsch, K.A., Jentsch, F.G., Payne, S.C. \& Sallas, E. 1996. Can pretraining experiences explain individual differences in learning? Journal of Applied Psychology, 80, 239-252.

Sullivan, R.L., Wircenski, J.L., Arnold, A.S. \& Sarkees, M.D.( 1990). A practical guide for the design, delivery and evaluation of training. Maryland: Aspen Publishers.

Tracey, J.B., Tannenbaum, S.I. \& Kavanagh, M.J. (1995). Applying trained skills on the job: the importance of the work environment. Journal of Applied Psychology, 80 (2), 239-252.

Veldsman, T.H. (1998). Exploring the living organization: the concept "organizational culture". In J.A. Slabbert; J.J. Prinsloo; B.J. Swanepoel; W. Backer (eds). Managing employment relations in South Africa ( pp18-1 - 18-25). Johannesburg: Butterworths.

Warr, P. \& Bunce, D. (1995). Trainee characteristics and the outcomes of open learning. Personnel Psychology, 48 (2), 347-375.

Watkins, KE \& Marsick, VJ (1993) Sculpting the Learning Organization. California:Jossey-Bass.

Xiao, J. (1996). Relationship between organisational factors and the transfer of training in the electronics industry. Human Resource Development Quarterly, 7 (1), 55-63. 